\title{
Atomic charges of sulfur in ionic liquids: experiments and calculations
}

Article

Accepted Version

Fogarty, R. M., Rowe, R., Matthews, R. P., Clough, M. T., Ashworth, C. R., Brandt, A., Corbett, P. J., Palgrave, R. G., Smith, E. F., Bourne, R. A., Chamberlain, T. W., Thompson, P. B. J., Hunt, P. A. and Lovelock, K. R. J. (2018) Atomic charges of sulfur in ionic liquids: experiments and calculations. Faraday Discussions, 206. pp. 183-201. ISSN 1364-5498 doi: https://doi.org/10.1039/c7fd00155j Available at https://centaur.reading.ac.uk/73432/

It is advisable to refer to the publisher's version if you intend to cite from the work. See Guidance on citing.

To link to this article DOI: http://dx.doi.org/10.1039/c7fd00155j

Publisher: The Royal Society of Chemistry

All outputs in CentAUR are protected by Intellectual Property Rights law, including copyright law. Copyright and IPR is retained by the creators or other copyright holders. Terms and conditions for use of this material are defined in the End User Agreement. 


\section{CentAUR}

Central Archive at the University of Reading

Reading's research outputs online 


\title{
Atomic Charges of Sulfur in lonic Liquids: Experiments and Calculations
}

Richard M. Fogarty, ${ }^{1}$ Rebecca Rowe, ${ }^{1}$ Richard P. Matthews, ${ }^{1}$ Matthew T. Clough, ${ }^{1}$ Claire R. Ashworth, ${ }^{1}$ Agnieszka Brandt, ${ }^{2}$ Paul J. Corbett, ${ }^{2}$ Robert G. Palgrave, ${ }^{3}$ Emily F. Smith, ${ }^{4}$ Richard A. Bourne, ${ }^{5,6}$ Thomas W. Chamberlain, ${ }^{6}$ Paul B. J. Thompson, ${ }^{7}$ Patricia A. Hunt, ${ }^{1}$ Kevin R. J. Lovelock. ${ }^{8}$

${ }^{1}$ Department of Chemistry, Imperial College London, UK

${ }^{2}$ Department of Chemical Engineering, Imperial College London, UK

${ }^{3}$ Department of Chemistry, University College London, UK

${ }^{4}$ School of Chemistry, University of Nottingham, UK

${ }^{5}$ School of Chemical and Process Engineering, University of Leeds, UK

${ }^{6}$ Institute of Process Research and Development, School of Chemistry, University of Leeds, UK

${ }^{7}$ XMaS, UK CRG, ESRF, France, and Department of Physics, University of Liverpool, UK

${ }^{8}$ Department of Chemistry, University of Oxford, UK

Contact E-mail: kevin.lovelock@chem.ox.ac.uk; p.hunt@imperial.ac.uk

\begin{abstract}
Experimental near edge X-ray absorption fine structure (NEXAFS) spectra, X-ray photoelectron (XP) spectra and Auger electron spectra are reported for sulfur in ionic liquids (ILs) with a range of chemical structures. These values provide experimental measures of the atomic charge in each IL and enable evaluation of the suitability of NEXAFS spectroscopy and XPS for probing relative atomic charge of sulfur. In addition, we use Auger electron spectroscopy to show that when XPS binding energies differ by less than $0.5 \mathrm{eV}$, conclusions on atomic charge should be treated with caution. Our experimental data provides a benchmark for calculations of atomic charge of sulfur obtained using different methods. Atomic charges were computed for lone ions and ion pairs, both in the gas phase (GP) and in a solvation model based on density (SMD), with a wide range of ion pair conformers considered. Three methods were used to compute atomic charges: charges from electrostatic potential using a grid based method (ChelpG), natural bond orbital (NBO) population analysis and Bader's atoms in molecules (AIM) approach. By comparing experimental and calculated measures of atomic charge of sulfur, we provide an order for the sulfur atoms, ranging from most negative to most positive atomic charge. Furthermore, we show that both ChelpG and NBO are reasonable methods for calculating atomic charge of sulfur in ILs, based on agreement with both XPS and NEXAFS spectroscopy results. However, atomic charges of sulfur derived from ChelpG are found to display significant, non-physical conformational dependence. Only small differences in individual atomic charge of sulfur were observed between lone ion (GP) and ion pair IL(SMD) model systems, indicating that ion-ion interactions do not strongly influence individual atomic charges.
\end{abstract}

\section{Introduction}

Ionic liquids (ILs) are substances composed solely of mobile ions. Many ILs possess desirable properties, e.g. electrical conductivity, low vapour pressure and a wide electrochemical window. 
ILs have a wide range of potential applications including as solvents in catalysis; ${ }^{1}$ materials for lubrication; ;2, 3 and electrolytes for electrodeposition, batteries and supercapacitors ${ }^{4,5}$.

Many physical properties of ILs are determined by the intermolecular ion-ion interactions, e.g. surface tension, ${ }^{6}$ vapour pressure ${ }^{7}$ and viscosity ${ }^{8}$. Therefore, understanding intermolecular interactions in ILs is key for establishing relationships between molecular-level (that is, ion composition) and macroscopic properties. Due to the ionic nature of ILs, Coulombic forces are major contributors to intermolecular interactions. Therefore, understanding the charge distribution of individual ions is key to understanding intermolecular interactions - and the related physical properties - in ILs.

The atomic charge of atom $A, q(A)$, is defined as $q(A)=Z_{A}-\rho_{A}$, where $Z_{A}$ is the atomic number of $A$ and $\rho_{A}$ is the electron density assigned to $A$ in an ion or molecule. ${ }^{9} q(A)$ values represent an intuitive way of understanding the complex distributions of valence electrons for molecules, and are used in classical molecular dynamics (MD) simulations to model Coulombic interactions. However, it is difficult to validate the many different methods for determining $q(A)$ values, as $q(\mathrm{~A})$ is a theoretical construct rather than an observable physical property.

A range of methods exist for assigning $q(\mathrm{~A})$ based on the electron density of a system. For example, population analysis (based on the electronic wavefunction), fitting to the electrostatic potential (ESP) and Bader's atoms in molecules (AIM) approach (based on the electron density). Population analysis methods involve expanding the density in terms of atomic orbitals (AOs), from which the electron density associated with each $\mathrm{AO}$ can be obtained. The electron density (and therefore, $q(A)$ ) associated with an atom is obtained by summation of the electron density in all the AOs centred on that atom. Some population analysis techniques (e.g. Mulliken) can be strongly dependent on the basis set, ${ }^{10}$ others such as the natural bond orbital (NBO) population analysis are largely basis set independent, as the electron density is expanded in terms of natural AOs rather than the basis functions used to calculate the density. ${ }^{11,12}$ ESP methods involve first calculating the ESP (from the electron density) at a set of fitting points. A fitting procedure is subsequently used to derive the set of $q(A)$ which best reproduces the ESP at each fitting point. Different ESP methods vary in the selection of points used to calculate the ESP; for example, a rectangular grid of points is used in the "charges from electrostatic potential using a grid based method" (ChelpG) method. ${ }^{13}$ The AIM method involves the analysis of the electron density topology. ${ }^{14,15}$ Electron density is divided into nuclear basins and the electron density associated with each nucleus (and therefore, $q(\mathrm{~A})$ ) is found by integrating the electron density within the associated nuclear basin.

For $a b$ initio calculations of ILs, there is a limit to the total number of ions that can be readily included in a single calculation, primarily due to the increase in computational cost. Most calculations of $q(A)$ for ILs have been carried out on ion pairs in the gas phase. ${ }^{16}$ We have recently obtained evidence that calculations on relatively small numbers of ions capture the liquid phase valence electronic structure (i.e. the valence band, (VB)) of ILs, in particular when a solvent continuum is employed. ${ }^{17}$ In addition, there is a very weak dependence of the calculated IL VB on ion pair conformation when a solvent continuum is employed. ${ }^{18}$ The solvent 
continuum employed here is a generalised liquid continuum model, the SMD (Solvation Model based on Density) model. ${ }^{19,20}$

Different methods for assigning $q(\mathrm{~A})$ for ILs have been shown to give different $q(\mathrm{~A})$. For example, $q(\mathrm{~N})$ for $\left[\mathrm{C}_{n} \mathrm{C}_{1} \mathrm{~lm}\right]^{+}(1,3$-dialkylimidazolium, where $n>0)$ can be either positive ${ }^{21-23}$ or negative 24,25 , depending on the method used to compute $q(\mathrm{~N})$. Results from classical MD simulations illustrate the strong effects of varying charge distribution on physical properties. Using different $q(\mathrm{~A})$ values for MD simulations significantly affects predicted structural, dynamic or energetic properties for both ILs and deep eutectic solvents. ${ }^{26-30}$ Viscosity was demonstrated to be particularly sensitive to the degree of charge transfer in an IL, scaling $q(A)$ values by $50 \%$ to $100 \%$ for $\left[\mathrm{C}_{1} \mathrm{C}_{1} \mathrm{Im}\right] \mathrm{Cl}$ led to calculated diffusion constants that spanned three orders of magnitude. ${ }^{31}$ Furthermore, charge transfer has also been used to explain why ILs often have a lower conductivity than diffusion coefficients would suggest. ${ }^{32}$ Despite the importance of charge distribution in MD simulations, different IL force fields use different $q(A)$ values.

$q(A)$ is not an observable physical property; only properties and/or quantities that are dependent on $q(\mathrm{~A})$ can be observed. Therefore, it is very difficult to validate computed values of $q(\mathrm{~A})$ against experimental data methods. Nonetheless, the validity of different $q(A)$ methods has been tested in various ways. Experimental $p K_{a}$ values for substituted anilines and phenols were found to correlate well with both AIM and NBO $q(\mathrm{~A})$, whereas ESP $q(\mathrm{~A})$ showed poor correlations. $^{33}$ By contrast, $q(\mathrm{~A})$ from ESP methods for single molecules were significantly better at reproducing (experimental or theoretical) dipole moments than population analysis methods (e.g. NBO). ${ }^{34}$ Purely computational criteria have been used to assess the validity of ESP and population analysis methods for ILs; the criteria included basis set dependence, consistency in $q(\mathrm{~A})$ for symmetrically equivalent atoms and invariance of $q(\mathrm{~A})$ as the alkyl chain length was increased for $\left[\mathrm{C}_{n} \mathrm{C}_{1} I \mathrm{~m}\right]^{+}{ }^{35}$ ESP methods and NBO both performed well, but other population analysis methods (e.g. Mulliken) were not recommended based on the strong basis set dependence of $q(\mathrm{~A})$. To the best of our knowledge, no study has attempted to validate $q(\mathrm{~A})$ methods in ILs by direct comparison to experimental results; the closest study was a comparison of experimental measures of charge density against total ion charge ${ }^{36}$ (but not $q(\mathrm{~A}))$.

X-ray photoelectron spectroscopy (XPS), near edge X-ray absorption fine structure (NEXAFS) spectroscopy and Auger electron spectroscopy (AES) can be used to understand charge distribution, and therefore have the potential to be used for validation of $q(A)$. XPS has historically been the principal technique for comparing how charge distributions differ between systems. ${ }^{37}$ All of these core-hole techniques are element specific - they each provide a local measure of electron density.

Core orbital electron binding energies $\left(E_{\mathrm{B}}\right)$, measured by XPS, are sensitive to the amount of valence electron density near a particular nucleus, and therefore to $q(\mathrm{~A})$ (Figure 1a). The $E_{\mathrm{B}}$ of core orbital $i$ is defined as the difference in energy between the ground (initial) state and an ionised (final) state with a core-hole in orbital $i$ (Equation 1). 


$$
E_{\mathrm{B}}=E_{\text {final }}-E_{\text {initial }}
$$

Each core orbital has a characteristic $E_{\mathrm{B}}$ value (e.g. S 1s $\sim 2475 \mathrm{eV}$ ). However, variations in the local environment (i.e. the interactions with nearby atoms) can cause measureable differences in $E_{\mathrm{B}}$. For example, negative $q(\mathrm{~A})$ destabilises core orbitals relative to the neutral atom, and therefore leads to a smaller $E_{\mathrm{B}}$ (Figure $1 \mathrm{a}(\mathrm{i})$ and Figure $1 \mathrm{a}(\mathrm{ii})$ ). Differences in $E_{\mathrm{B}}$ that are caused by varying amounts of electron density near the ground-state atom, i.e. $q(\mathrm{~A})$, are called initial state effects. A significant problem with interpreting shifts in $E_{B}$ as differences in $q(A)$ is that electronic relaxation can occur on the femtosecond timescale of the photoelectric effect. This relaxation gives a second source of $E_{\mathrm{B}}$ differences due to the varying ability of different systems to stabilise a core-hole; this is known as a final state effect (effects which occur after a core-hole is formed). ${ }^{37,38}$ Interpretation of $E_{B}$ shifts in terms of $q(A)$ relies on the magnitude of the final state effects being similar in the systems studied. Linear relationships between calculated $q(A)$ and core orbital $E_{B}$ values have previously been found for both carbon and sulfur in a wide range of solid compounds. ${ }^{39-43}$ Furthermore, for IL systems, shifts in $E_{\mathrm{B}}$ have routinely been interpreted as being due to changes in $q(A),{ }^{36,44-50}$ although only one paper contains any comparison to calculated charge distributions. ${ }^{36}$

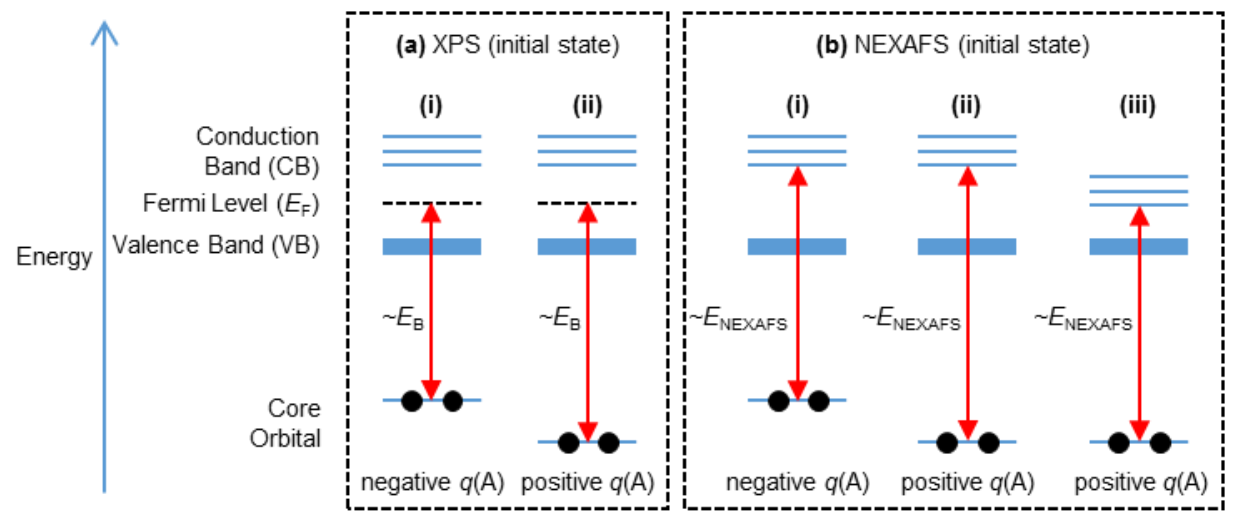

Figure 1. (a) The effects of atomic charge, $q(\mathrm{~A})$, on experimental electron binding energies $\left(E_{\mathrm{B}}\right)$ in X-ray photoelectron spectroscopy (XPS), assuming only initial states effects apply. (i) a negative $q(\mathrm{~A})$ gives a smaller $E_{\mathrm{B}}$ than (ii) a positive $q(\mathrm{~A})$. (b) The effects of atomic charge, $q(\mathrm{~A})$, and conduction band (CB) energies on experimental edge energies ( $E_{\text {NEXAFS }}$ ) in near-edge Xray absorption fine structure (NEXAFS) spectroscopy, assuming only initial states effects apply. (i) a negative $q(A)$ gives a smaller $E_{\text {NEXAFS }}$ than (ii) a positive $q(A)$, assuming the $C B$ energies are the same for both (i) and (ii). Differences in the CB energies can lead to differences in

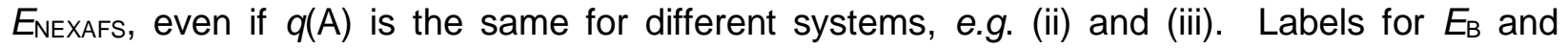
$E_{\text {NEXAFS }}$ only refer to the approximate quantities. The energy y-axis is not to scale. Final states (not shown in this figure) will also affect $E_{\mathrm{B}}$ and $E_{\mathrm{NEXAFS}}$ (see main text for more details).

The magnitude of final state effects on measured $E_{\mathrm{B}}$ can be probed by AES. An Auger transition is the process whereby a core-hole is filled by an electron from an orbital with smaller $E_{\mathrm{B}}$ than the orbital with the core-hole. The energy released by this process can cause emission of an electron from an orbital that also has smaller $E_{\mathrm{B}}$ than the core-hole orbital, which is termed the Auger electron (Figure S1). A specific Auger process is defined by identifying the 
orbitals which contain the initial core-hole, the electron which fills the core-hole, and the orbital from which the Auger electron is emitted. The energy of an Auger electron can be used to quantify differences in final state effects between different systems through the modified Auger parameter $(\beta): 51,52$

$$
\beta=E_{\mathrm{k}}(\mathrm{k}, \mathrm{i}, \mathrm{i})+2 E_{\mathrm{B}}(\mathrm{i})-E_{\mathrm{B}}(\mathrm{k})
$$

where $E_{\mathrm{K}}$ is the kinetic energy of an Auger electron from the Auger process involving orbitals $k$ and $i$ (with the initial core-hole located on orbital $k$ ), $E_{\mathrm{B}}(\mathrm{i})$ refers to the electron binding energy of orbital $i$ and $E_{\mathrm{B}}(\mathrm{k})$ refers to the electron binding energy of orbital $k$. More positive values of $\beta$ correspond to larger final state effects. The difference in final state effects between two systems is equal to $0.5 \Delta \beta .{ }^{51,52}$

NEXAFS spectroscopy is used to probe the energy required to promote an electron from a core orbital to the conduction band $(\mathrm{CB})$. The edge energy ( $E_{\mathrm{NEXAFS}}$ ) is defined as the lowest energy allowed transition for a core orbital $\rightarrow$ CB transition. E ENEXFS is commonly interpreted in terms of oxidation state, which can be thought of as integer values of $q(\mathrm{~A})$. Smaller $E_{\text {NEXAFs }}$ corresponds to a more negative $q(\mathrm{~A})$, due to negative charge destabilising core orbitals (Figure $1 \mathrm{~b}(\mathrm{i})$ and $1 \mathrm{~b}(\mathrm{ii})){ }^{53-58}$ An advantage of NEXAFS spectroscopy over XPS is that final state effects are less significant for NEXAFS spectroscopy than for XPS, as the final state has the same charge as the initial state in NEXAFS spectroscopy, whereas in XPS the final state is +1 relative to the initial state. A drawback of NEXAFS spectroscopy is the dependence of $E_{\text {NEXAFS }}$ on the CB energy of a system (as well as on $q(A)$ ) Figure $1 b$ (ii) and $1 b$ (iii). Hence, interpreting $E_{\text {NEXAFs }}$ in terms of $q(\mathrm{~A})$ relies on similar energy CBs across the systems studied, Figure $1 \mathrm{~b}(\mathrm{i})$ and $1 \mathrm{~b}(\mathrm{ii})$.

We have experimentally probed the relative atomic charge of sulfur in different chemical environments by measuring $E_{\mathrm{B}}$ and $E_{\mathrm{NEXAFS}}$ for a range of ILs (Figure 2 shows the structures of the ions studied). Furthermore, contributions from final state effects to $E_{\mathrm{B}}$ have been probed by measuring the $\beta$ parameter. $q(\mathrm{~S})$ has been calculated using three methods: AIM, ChelpG and NBO. The effects on $q(S)$ of different conformations and the addition of an IL(SMD) solvent continuum model have been investigated. The validity of the three methods has been tested by comparing calculated $q(\mathrm{~S})$ with the experimental measures of the electron density near sulfur. Trends in $q(\mathrm{~S})$ have been determined for the ILs studied by combining experimental and computational results. 


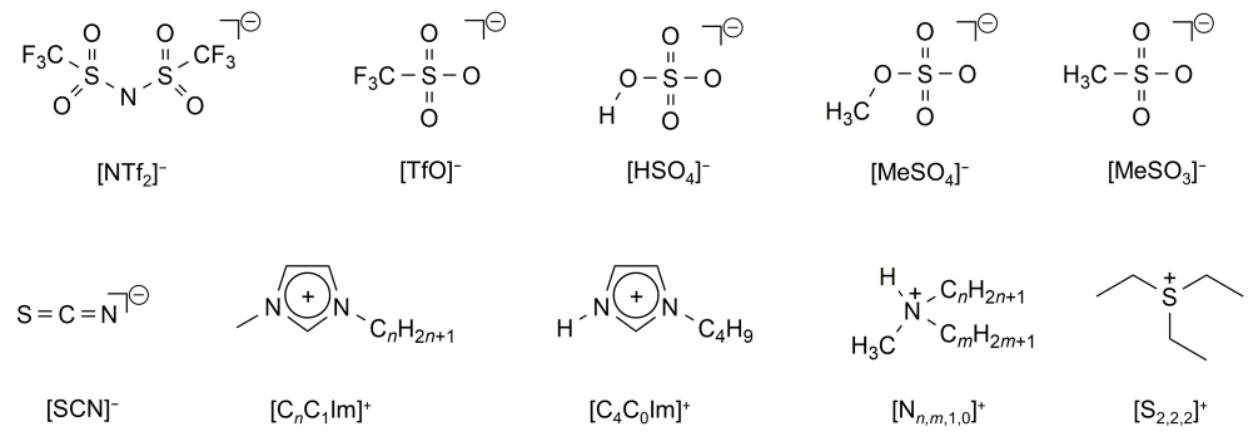

Figure 2: Structures and abbreviations for the ions studied in this work. The ions shown in the top row are referred to collectively as $\left[\mathrm{YSO}_{x}\right]^{-}$ions. 


\section{Methods}

\subsection{Experimental Methods}

$\left[\mathrm{N}_{8,1,1,0}\right]\left[\mathrm{HSO}_{4}\right]$ and $\left[\mathrm{N}_{2,1,1,0}\right][\mathrm{TfO}]$ were purchased from lolitec. $\left[\mathrm{C}_{8} \mathrm{C}_{1} \mathrm{Im}\right][\mathrm{TfO}],\left[\mathrm{S}_{2,2,2}\right]\left[\mathrm{NTf}_{2}\right]$ and $\left[\mathrm{C}_{4} \mathrm{C}_{1} \mathrm{Im}\right][\mathrm{SCN}]$ were purchased from Sigma-Aldrich. [ $\left.\mathrm{N}_{4,1,1,0}\right]\left[\mathrm{HSO}_{4}\right], \quad\left[\mathrm{C}_{2} \mathrm{C}_{1} \mathrm{Im}\right]\left[\mathrm{MeSO}_{3}\right]$, $\left[\mathrm{C}_{8} \mathrm{C}_{1} \mathrm{Im}\right]\left[\mathrm{NTf}_{2}\right], \quad\left[\mathrm{C}_{8} \mathrm{C}_{1} \mathrm{Im}\right]\left[\mathrm{HSO}_{4}\right], \quad\left[\mathrm{C}_{8} \mathrm{C}_{1} \mathrm{Im}\right] \mathrm{Cl}$ and $\left[\mathrm{C}_{4} \mathrm{C}_{0} \mathrm{Im}\right]\left[\mathrm{HSO}_{4}\right]$ were synthesised and characterised by established literature methods. ${ }^{59,60}$ All ILs were used without further purification, although it must be noted that as all experiments were carried out at system pressures $<10^{-7}$ mbar all volatile impurities (e.g. water) will have been removed before the X-ray spectroscopy data was recorded; purity was confirmed using XP survey and core orbital spectra (ESI Figure S2 to S16).

$\mathrm{XP}$ spectra used to obtain the reported $S 2 \mathrm{p}_{3 / 2} E_{\mathrm{B}}$ values were recorded using a monochromatic Al Ka $(h v=1486.6 \mathrm{eV})$ source at University College London. XP and Auger spectra which were used to obtain $\beta$ values were measured using a monochromatic Ag L $\alpha$ ' ( $h v=2984.6 \mathrm{eV}$ ) source at the University of Nottingham.

All XP spectra were fitted using CasaXPS ${ }^{\mathrm{TM}}$ software. Spectra were fitted with a GL30 lineshape (70\% Gaussian, 30\% Lorentzian) and a Shirley background. Relative sensitivity factors from ref ${ }^{61}$ were used to ensure the elemental stoichiometry of each sample matched the theoretical stoichiometry. ${ }^{61}$ In order to compare $E_{\mathrm{B}}$ values between different samples it is necessary to charge reference spectra $^{62}$ Spectra for imidazolium-based ILs were charge referenced by shifting all core orbitals; details are given in the ESI, section 4 . Previous results suggest that this charge referencing procedure will only introduce small errors $( \pm 0.1 \mathrm{eV})$ into the reported core-level $E_{\mathrm{B}}{ }^{62}$ These errors are accounted for in the reported $E_{\mathrm{B}}$ error margins $( \pm 0.2$ $\mathrm{eV})$.

All NEXAFS spectra were recorded on BM28 (XMaS beamline) at the European Synchrotron Radiation Facility (ESRF). ${ }^{63}$ A drop of each IL sample was deposited (using a spatula) onto a stainless steel sample holder and pumped down to $10^{-7}$ mbar. Fluorescence detection mode was used for all scans. A smoothing spline was fitted to the raw data using MATLAB ${ }^{\mathrm{TM}}$ Curve Fitting Toolbox, from which the first derivative spectrum was generated (ESI Figure S17). $E_{\text {NEXAFS }}$ is defined as the energy of the first peak in the first derivative spectrum.

\subsection{Computational Methods}

All calculations were carried out using the B3LYP functional and the $6-311+G(d, p)$ basis set, as implemented in Gaussian 09. ${ }^{64-70}$ Dispersion was accounted for using Grimme's D3 dispersion correction with Becke-Johnson damping. ${ }^{71-74}$ The self-consistent field (scf) convergence criteria were $10^{-9}$ on the density matrix and $10^{-7}$ on the energy matrix. The numerical integration grid was improved from the Gaussian 09 defaults to a pruned grid with 99 radial shells and 590 angular points per shell. 
Calculations were carried out using three different model systems. An isolated ion in the gas phase (GP) is referred to as lone ion (GP), a single cation with a single anion in the gas phase is referred to as an ion pair (GP), and a single cation and anion surrounded by the SMD solvent continuum model is referred to as an ion pair IL(SMD).

Optimisations were carried out under no symmetry constraints. The SMD solvent continuum model parameterised for $\left[\mathrm{C}_{4} \mathrm{C}_{1} I \mathrm{Im}\right]\left[\mathrm{PF}_{6}\right]$ was employed for all SMD calculations (parameters taken from ref $\left.{ }^{20}\right) .{ }^{19,} 20$ lon pair structures were initially optimised in the gas phase for all of the ILs studied, using starting structures based on stable ion pairs reported for $\left[\mathrm{C}_{4} \mathrm{C}_{1} 1 \mathrm{~m}\right] \mathrm{Cl}^{75}$ Stable gas phase conformers were used as starting structures for optimisation using the SMD continuum model. However, multiple gas phase minima were unstable in our IL solvent continuum model. Hence, fewer conformers were obtained for SMD calculations (see ESI Table S2). Frequency analysis was carried out for all structures and the absence of imaginary frequencies confirmed all structures as minima. Optimised structures, relative Gibbs Free energies, scf energies and selected charges are presented in the ESI Part 6.

In order to save computational expense, for all calculations on imidazolium-based ILs the $\left[\mathrm{C}_{4} \mathrm{C}_{1} \mathrm{Im}\right]^{+}$cation was used, although many of the experimental results are for the $\left[\mathrm{C}_{8} \mathrm{C}_{1} 1 \mathrm{~m}\right]^{+}$ cation. This choice is justified as $S$ 1s $E_{\text {NEXAFS }}$ was found to be independent of alkyl chain length for $\left[\mathrm{C}_{n} \mathrm{C}_{1} \mathrm{Im}\right]\left[\mathrm{NTf}_{2}\right] \mathrm{ILs}$ (ESI Figure S18 and Table S3) and sulfur $E_{\mathrm{B}}$ was previously found to be independent of chain length for a range of ILs. ${ }^{44,49,50,62}$

AIM $q(\mathrm{~S})$ were calculated using AIMAll software. ${ }^{76}$ NBO $q(\mathrm{~S})$ were calculated using NBO version 5.9 software, over-riding the default version implemented within Gaussian. ${ }^{77}$ ChelpG $q(S)$ were calculated within Gaussian. Ion pair IL(SMD) charges are derived from calculations using both the structure and density optimised within the SMD model. Unless otherwise stated, the values of $q(A)$ reported for an IL were calculated from an unweighted average of all ion pair conformers. This approach was chosen owing to its simplicity and the inherent difficulty in justifying any other method. However, the averaging approach makes little difference to the calculated atomic charges, due to their (generally) low conformational dependence (ESI Part 6). 


\section{Results}

\subsection{X-ray spectroscopy}

The S 2p XP spectra for nine of the 10 ILs (Figure 3a) show two peaks in a 2:1 area ratio (S $2 p_{3 / 2}: S 2 p_{1 / 2}$ ), which results from spin-orbit coupling of the unpaired core electron in the final state. Therefore, for each of these nine ILs there is only one sulfur electronic environment. For $\left[\mathrm{C}_{8} \mathrm{C}_{1} / \mathrm{m}\right]\left[\mathrm{NTf}_{2}\right]$ there is effectively only one sulfur electronic environment as the two sulfur atoms in $\left[\mathrm{NTf}_{2}\right]^{-}$are indistinguishable by XPS (Figure 3a). The $\left[\mathrm{S}_{2,2,2}\right]\left[\mathrm{NTf}_{2}\right] \mathrm{S} 2 \mathrm{p}$ XP spectrum shows four peaks, indicating two clearly distinct sulfur electronic environments (Figure 3a); the cationic contribution can readily assigned to the $S 2 p$ peak at $166.3 \mathrm{eV}$. $E_{\mathrm{B}}$ values were also measured for the $S 1 s$ edge and were found to correlate linearly with the $S 2 p_{3 / 2} E_{B}$ values (ESI Figure $S 19$, Table $S 4)$. $E_{B}$ of the more intense $S 2 p$ peak, $S 2 p_{3 / 2}$, was used to interpret the atomic charges, $q(\mathrm{~S})$, and will be referred to as simply $S 2 p$ henceforth.

All sulfur $\mathrm{KL}_{2,3} \mathrm{~L}_{2,3}$ Auger spectra, except for $\left[\mathrm{S}_{2,2,2}\right]\left[\mathrm{NTf}_{2}\right]$, show a single distinct, sharp peak (ESI Figures $\mathrm{S} 12$ to $\mathrm{S} 16)$, further confirming that ILs apart from $\left[\mathrm{S}_{2,2,2}\right]\left[\mathrm{NTf}_{2}\right]$ contain sulfur in only one electronic environment. The $\left[\mathrm{S}_{2,2,2}\right]\left[\mathrm{NTf}_{2}\right] \mathrm{S} \mathrm{KL}_{2,3} \mathrm{~L}_{2,3}$ spectrum (ESI Figure $\mathrm{S} 13$ ) has two peaks; the peak at $E_{\mathrm{K}}=2108.9 \mathrm{eV}$ can readily be assigned to the cationic sulfur atom by comparison to the $S \mathrm{KL}_{2,3} \mathrm{~L}_{2,3}$ spectrum for $\left[\mathrm{C}_{8} \mathrm{C}_{1} \mathrm{Im}\right]\left[\mathrm{NTf}_{2}\right]$ (ESI Figure $\mathrm{S14}$ ).

The $S$ 1s NEXAFS spectral shapes vary significantly for sulfur in different chemical environments. For example, a reasonably sharp peak was observed for $\left[S_{2,2,2}\right]^{+}$, whereas a broad feature was present for [SCN]- (Figure 3b). The varying shapes of NEXAFS spectra for different ILs are due to differences in the excited states probed, i.e. differences in the density of unoccupied states. As not all S 1s NEXAFS spectra exhibited clearly defined peaks, we chose to use $E_{\text {NEXAFS }}$ as our best measure of the relative atomic charge of sulfur (as opposed to using the peak energy). More detail is given in the methods section on how $E_{\text {NEXAFS }}$ values were obtained.

Larger values of $E_{\mathrm{B}}$ (for both $S 2 p$ and $S 1 s$ ) and $S$ 1s $E_{\text {NEXAFS }}$ broadly indicate more positive values of $q(\mathrm{~S})$. Both $E_{\mathrm{NEXAFS}}$ and $E_{\mathrm{B}}\left(\mathrm{S} 2 \mathrm{p}_{3 / 2}\right.$ and $\left.S 1 \mathrm{~s}\right)$ increased in the order: $[\mathrm{SCN}]^{-}<\left[\mathrm{S}_{2,2,2}\right]^{+}<$ $\left[\mathrm{YSO}_{x}\right]^{-}$. [YSO $]^{-}$-based ILs are grouped together at this stage as $E_{\mathrm{B}}$ and $E_{\mathrm{NEXAFS}}$ suggest different $q(\mathrm{~S})$ ordering within these ILs. Varying the counter cation was found to have no effect on $q(\mathrm{~S})$ for $\left[\mathrm{YSO}_{x}\right]^{-}$-based ILs, evidenced by the identical $E_{\mathrm{B}}$ and $E_{\mathrm{NEXAFS}}$ values, within the experimental error, for systems with the same anion but with a different cation (Table 1, e.g. $\left[\mathrm{N}_{2,1,1,0}\right][\mathrm{TfO}]$ compared to $\left.\left[\mathrm{C}_{8} \mathrm{C}_{1} \mathrm{Im}\right][\mathrm{TfO}]\right)$.

The contribution of final state effects to sulfur $E_{\mathrm{B}}$ values was quantified by measuring the modified Auger parameter ( $\beta$ ) (Table 1, ESI Table S4). Larger (more positive) values of $\beta$ indicate greater final state effects. The order of final state effects was found to be $[\mathrm{SCN}]^{-}<$ $\left[\mathrm{YSO}_{x}\right]^{-}<\left[\mathrm{S}_{2,2,2}\right]^{+}$(Table 1). Differences in $\beta$ for $\left[\mathrm{YSO}_{x}\right]^{-}$ILs (those containing $\left[\mathrm{NTf}_{2}\right]^{-},\left[\mathrm{TfO}^{-}\right.$, $\left[\mathrm{HSO}_{4}\right]^{-},\left[\mathrm{MeSO}_{3}\right]^{-}$and $\left[\mathrm{MeSO}_{4}\right]^{-}$ions) were all well within the experimental error. Therefore, these systems are interpreted as having final state effects of the same magnitude. When 
interpreting $E_{B}$ values in terms of $q(A)$ only differences greater than the expected final state effects, i.e. $0.5 \Delta \beta$ values, should be considered. Our $0.5 \Delta \beta$ values span a range of $0.5 \mathrm{eV}$, which suggests differences in $E_{\mathrm{B}}<0.5 \mathrm{eV}$ should be treated with care when interpreting $E_{\mathrm{B}}$ shifts in terms of $q(\mathrm{~A})$ for ILs.
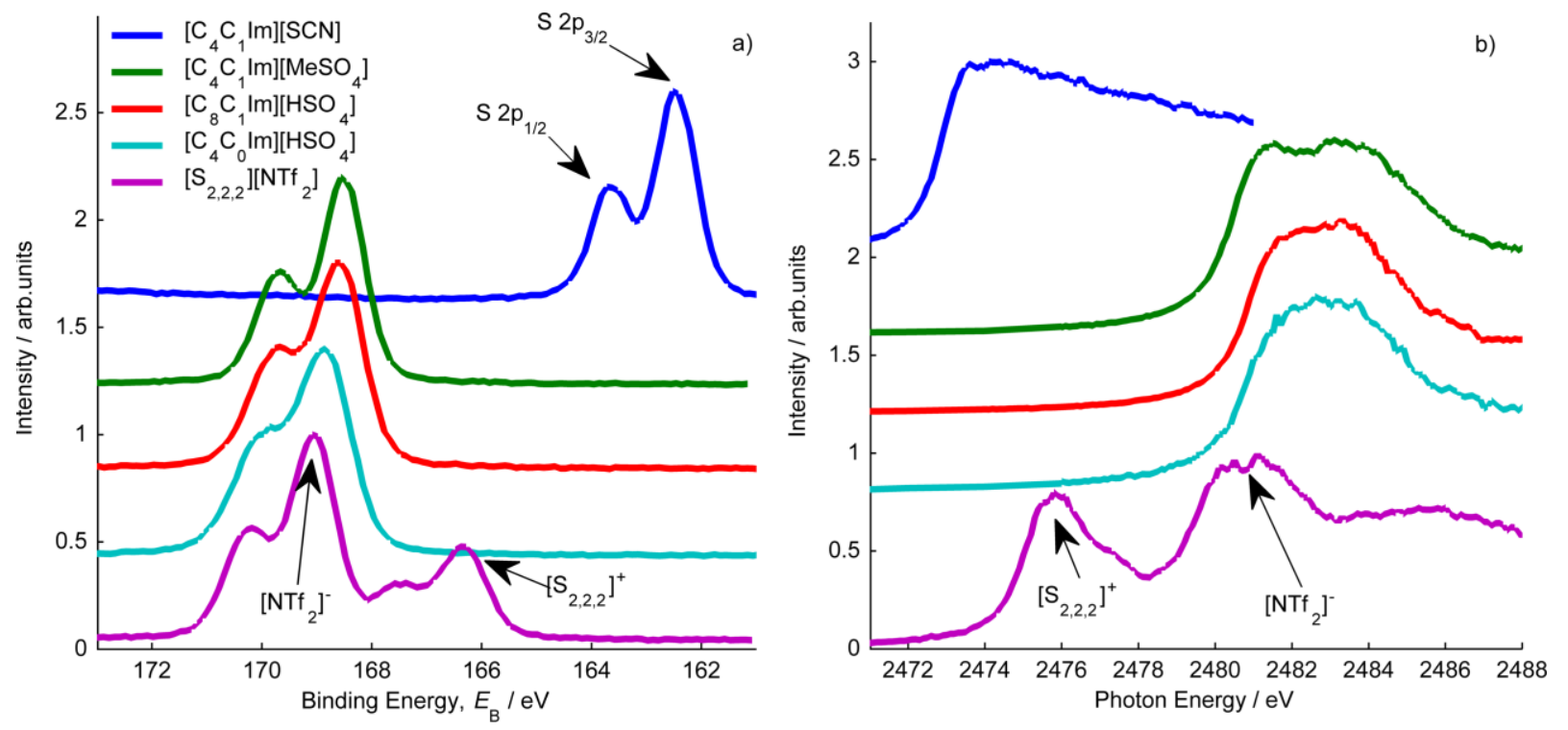

Figure 3. a) S 2p XP spectra and b) $S$ 1s NEXAFs spectra for five ILs (see Figure S2 to S16 for spectra of all 10 ILs). All XP spectra have been charge referenced (see ESI Part 4, Table S1 for details). 


\begin{tabular}{|c|c|c|c|c|c|c|c|c|c|}
\hline & Ion $\mathrm{p}$ & $\operatorname{iir}(\mathrm{GP})$ & $q(\mathrm{~S}) / e$ & Experimente & X-ray spectr & scopy & & & \\
\hline System & AIM & NBO & ChelpG & $\begin{array}{l}\mathrm{S} 2 \mathrm{p}_{3 / 2} E_{\mathrm{B}} \\
( \pm 0.2) / \mathrm{eV}\end{array}$ & $\begin{array}{l}\text { S 1s } E_{\mathrm{NEXAFS}} \\
( \pm 0.1) / \mathrm{eV}\end{array}$ & $\begin{array}{l}\text { S 1s } E_{B} \\
( \pm 0.2) / e V\end{array}$ & $\begin{array}{l}\mathrm{S} \mathrm{KL}_{2,3} \mathrm{~L}_{2,3} \\
E_{\mathrm{K}} / \mathrm{eV}\end{array}$ & $\beta( \pm 0.6) / \mathrm{eV}$ & $\begin{array}{l}\frac{\Delta \beta}{2}( \pm 0.3) / \\
\mathrm{eV}\end{array}$ \\
\hline$\left[\mathrm{C}_{4} \mathrm{C}_{1} \mathrm{Im}\right][\mathrm{SCN}]$ & -0.1 & -0.4 & -0.5 & 162.4 & 2472.9 & 2470.6 & 2111.5 & -34.3 & 0.0 \\
\hline$\left[\mathrm{S}_{2,2,2}\right]\left[\mathrm{NTf}_{2}\right]$ (cation) & 0.3 & 0.8 & 0.0 & 166.3 & 2475.0 & 2474.8 & 2108.9 & -33.3 & 0.5 \\
\hline$\left[\mathrm{S}_{2,2,2}\right]\left[\mathrm{NTf}_{2}\right]$ (anion) & 3.0 & 2.1 & 1.0 & 169.0 & 2479.5 & 2478.6 & 2106.6 & -34.0 & 0.2 \\
\hline$\left[\mathrm{C}_{8} \mathrm{C}_{1} \mathrm{~lm}\right]\left[\mathrm{NTf}_{2}\right]$ & 3.0 & 2.1 & 1.0 & 169.0 & 2479.7 & 2478.4 & 2106.7 & -33.7 & 0.3 \\
\hline$\left[\mathrm{C}_{2} \mathrm{C}_{1} \mathrm{Im}\right]\left[\mathrm{MeSO}_{3}\right]$ & 3.0 & 2.3 & 1.4 & 167.8 & 2480.1 & 2477.3 & 2107.6 & -33.8 & 0.3 \\
\hline$\left[\mathrm{N}_{2,1,1,0}\right][\mathrm{TfO}]$ & 3.1 & 2.2 & 1.0 & 168.6 & 2480.1 & & & & \\
\hline$\left[\mathrm{C}_{8} \mathrm{C}_{1} \mathrm{Im}\right][\mathrm{TfO}]$ & 3.2 & 2.2 & 1.1 & 168.6 & 2480.1 & 2478.2 & 2106.7 & -34.3 & 0.0 \\
\hline$\left[\mathrm{C}_{4} \mathrm{C}_{1} \mathrm{Im}\right]\left[\mathrm{MeSO}_{4}\right]$ & 3.5 & 2.5 & 1.3 & 168.4 & 2480.4 & 2477.9 & 2107.3 & -33.8 & 0.3 \\
\hline$\left[\mathrm{C}_{8} \mathrm{C}_{1} \mathrm{Im}\right]\left[\mathrm{HSO}_{4}\right]$ & 3.5 & 2.4 & 1.5 & 168.6 & 2480.9 & 2478.2 & 2107.0 & -34.0 & 0.2 \\
\hline$\left[\mathrm{C}_{4} \mathrm{C}_{0} \mathrm{Im}\right]\left[\mathrm{HSO}_{4}\right]$ & 3.5 & 2.5 & 1.4 & 168.9 & 2480.9 & & & & \\
\hline$\left[\mathrm{N}_{4,1,1,0}\right]\left[\mathrm{HSO}_{4}\right]$ & 3.5 & 2.5 & 1.4 & $168.7^{*}$ & 2480.9 & & & & \\
\hline $\mathrm{S}_{8}$ powder & & & & 163.8 & 2471.8 & & & & \\
\hline
\end{tabular}

Table 1. Calculated and experimental X-ray spectroscopy data for a range of ILs and $S_{8}$. The values given are for calculated atomic charge of sulfur $(q(S))$, measured sulfur $2 p_{3 / 2}$ binding energies $\left(E_{\mathrm{B}}\right)$, S $1 \mathrm{~s}$ NEXAFS edge energies $\left(E_{\mathrm{NEXAFS}}\right)$, sulfur $1 \mathrm{~s}$ binding energies $\left(E_{\mathrm{B}}\right), S \mathrm{KL}_{2,3} \mathrm{~L}_{2,3}$ Auger kinetic energies $\left(E_{\mathrm{K}}\right)$, modified Auger parameters $(\beta)$ and $\frac{\Delta \beta}{2}$. Note that half of the error for $E_{\mathrm{B}}$ comes from charge referencing, and hence does not propagate through to the error on $\beta$. Calculated $q(\mathrm{~S})$ are from an unweighted average of all gas phase (GP) ion pair conformers. In cases for which $\left[\mathrm{C}_{8} \mathrm{C}_{1} \mathrm{Im}\right]^{+}$was the cation, $\mathrm{a}\left[\mathrm{C}_{4} \mathrm{C}_{1} \mathrm{Im}\right]^{+}$cation was used in the calculation of $q(\mathrm{~S}) .{ }^{*}\left[\mathrm{~N}_{8,1,1,0}\right]\left[\mathrm{HSO}_{4}\right]$ was used to obtain the $E_{\mathrm{B}}$ value. See ESI Part 5 for more details on the $S 2 p_{3 / 2} E_{\mathrm{B}}$ value for $\mathrm{S}_{8}$. 


\subsection{Calculated $q(\mathbf{S})$}

\subsubsection{Trends in $q(\mathrm{~S})$}

The calculated ion pair (GP) $q(\mathrm{~S})$ values follow almost the same ordering for the three $q(\mathrm{~S})$ calculation methods tested (the position of $\left[\mathrm{MeSO}_{3}\right]^{-}$in the order slightly differs for the three charge methods). This order is unchanged by addition of the solvent continuum model (Figure 4, ESI Table S5 and Figures S21 and S22); going from ion pair (GP) to ion pair IL(SMD) leads to only small changes $(<0.1 \mathrm{e})$ in the calculated values of $q(\mathrm{~S})$ (ESI Figure S21). Calculated $q(\mathrm{~S})$ increases (becomes more positive) in the order $[\mathrm{SCN}]^{-}<\left[\mathrm{S}_{2,2,2}\right]^{+}<\left[\mathrm{NTf}_{2}\right]^{-}<\left[\mathrm{TfO}^{-} \approx\right.$ $\left[\mathrm{MeSO}_{3}\right]^{-}<\left[\mathrm{MeSO}_{4}\right]^{-} \approx\left[\mathrm{HSO}_{4}\right]^{-}$. The identity of the counterion does not significantly affect calculated $q(\mathrm{~S})$ values (Table 1).

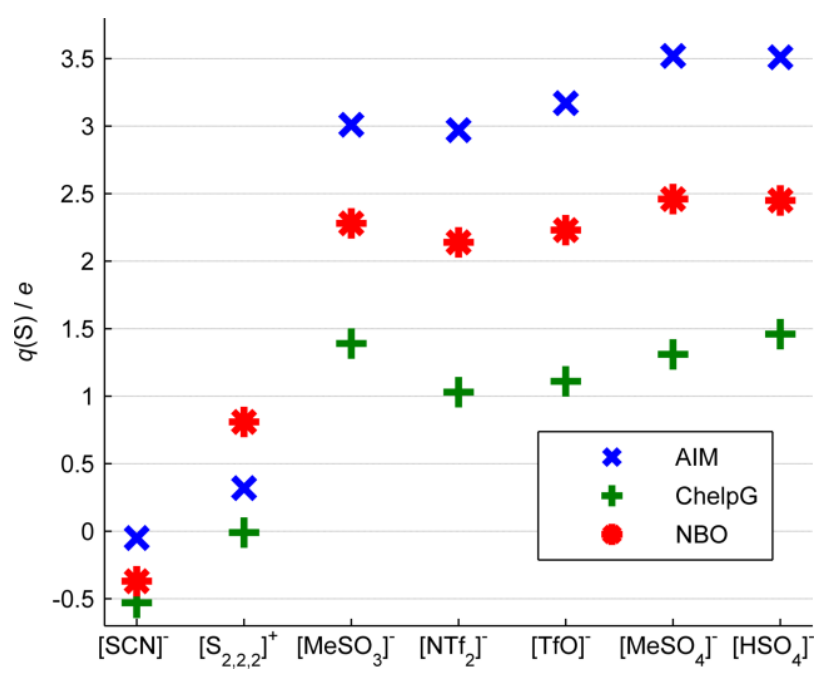

Figure 4. Calculated ion pair gas phase (GP) atomic charge of sulfur, $q(\mathrm{~S})$, for seven different ions with three $q(\mathrm{~S})$ calculation methods. Charges were taken from $\left[\mathrm{C}_{4} \mathrm{C}_{1} \mathrm{Im}\right][\mathrm{A}]$ calculations in cases in which an ion was calculated with multiple counterions (e.g. the $\left[\mathrm{HSO}_{4}\right]^{-} q(\mathrm{~S})$ in this plot is from $\left[\mathrm{C}_{4} \mathrm{C}_{1} \operatorname{lm}\right]\left[\mathrm{HSO}_{4}\right]$, not $\left.\left[\mathrm{N}_{4,1,1,0}\right]\left[\mathrm{HSO}_{4}\right]\right)$. For each $\mathrm{IL}$, calculated $q(\mathrm{~S})$ are from an unweighted average of all ion pair (GP) conformers.

\subsubsection{Effects of ion-ion interactions on $q(S)$}

The effects of ion-ion interactions on $q(\mathrm{~A})$ can be probed by comparing $q$ from model systems without any ion-ion interactions (i.e. lone ions (GP)) to those with ion-ion interactions (e.g. ion pair IL(SMD)). Effects of ion-ion interactions on $q(S)$ are therefore quantified as the difference in $q(\mathrm{~S})$ between ion pair IL(SMD) and lone ion (GP) model systems, $\Delta q(\mathrm{~S})$. ChelpG charges show the largest $\Delta q(\mathrm{~S})$ values, e.g. $\Delta q(\mathrm{~S}) \sim 0.2$ e for $\left[\mathrm{N}_{2,2,1,0}\right][\mathrm{TfO}]$ and $\left[\mathrm{S}_{2,2,2}\right]\left[\mathrm{NTf}_{2}\right]$ (sulfur in the anion). ChelpG charges (compared to AIM and NBO) also show the strongest dependence on model system size for $q(C)$ in $\left[\mathrm{C}_{4} \mathrm{C}_{1} \mathrm{Im}\right][\mathrm{A}] \mathrm{ILs}$. However, we believe the (relatively) strong dependence of ChelpG charges on model system size are artefacts of the fitting process, rather than physical effects, for reasons discussed in Section 4.2. 
For AIM and NBO, the largest $\Delta q(\mathrm{~S})$ is $\sim 0.1 e$ (Figure 5). Lone ions (GP) and ion pair IL(SMD) model systems also lead to similar AIM and NBO $q(C)$ values for the three carbon atoms from the imidazolium ring (Figure S27). Furthermore, AIM and NBO $q(\mathrm{~N})$ and $q(\mathrm{H})$ values for the $\mathrm{N}-$ $\mathrm{H}$ group of protic ammonium ILs are found to be similar for lone ions (GP) and ion pair IL(SMD), despite the strong anion-cation hydrogen bond (ESI Table S7). Overall, ion-ion interactions do not appear to strongly affect individual atomic charges for the ILs studied. Therefore, the charge distribution of an ion in the bulk of an IL appears to be broadly similar to the gas phase charge distribution. Nonetheless, it is possible that even seemingly small changes in atomic charge for multiple atoms can add up to a significant amount of charge transfer, which may affect the dynamic properties of ILs.

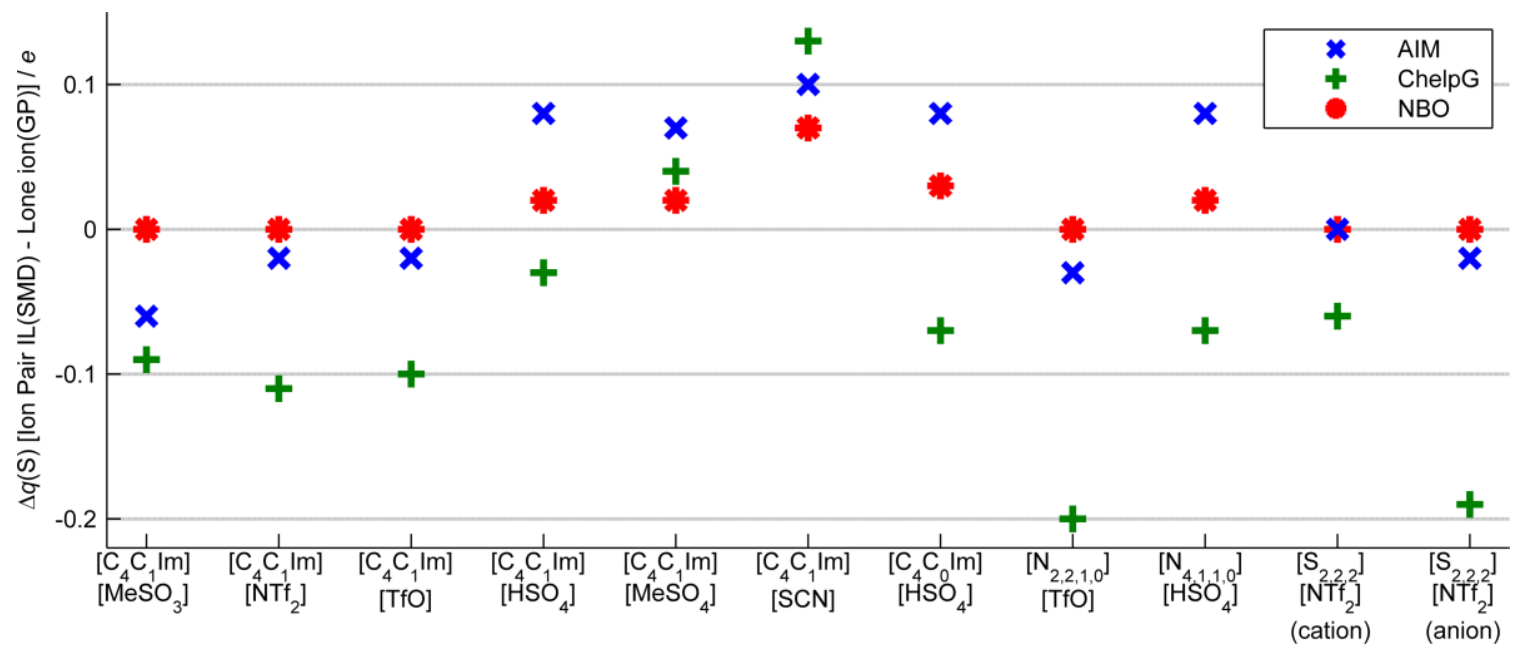

Figure 5. Difference in atomic charge of sulfur, $\Delta q(\mathrm{~S})$, between the ion pair IL(SMD) model system and the lone ion (GP) model system. $q(\mathrm{~S})$ values are from an unweighted average of conformers.

\subsubsection{Ion pair conformational dependence}

Multiple ion pair (GP) conformer structures were studied for each IL to investigate the conformational dependence of atomic charges calculated with the three methods (Figure 6, ESI Figures S24 and S25, Table S6). Conformational dependence of $q(A)$ can be quantified using the range of calculated $q(\mathrm{~A})$, which is defined as the maximum $q(\mathrm{~A})$ calculated for a conformer minus the minimum $q(S)$ calculated for a conformer. AIM and NBO methods showed very low conformational dependence for both $q(\mathrm{~S})$ and $q(\mathrm{C})$ values, with a range of $<0.1 e$ in all cases except for $\left[S_{2,2,2}\right]\left[\mathrm{NTf}_{2}\right]$ (explained below). ChelpG $q(\mathrm{~S})$ showed greater conformational dependence, with a range of 0.1 e to 0.3 e for the majority of ILs studied.

Addition of the IL(SMD) model to ion pair (GP) structures lowers the ion pair conformational dependence of AIM and NBO $q(\mathrm{~S})$ for all systems studied, illustrated by a decreased $q(\mathrm{~S})$ range for different conformers (ESI Figure S29,S33). The decrease of AIM and NBO $q(\mathrm{~S})$ conformational dependence is expected, based on the weak dependence of valence electronic structure on conformation when an $\mathrm{IL}(\mathrm{SMD})$ is employed. ${ }^{18}$ Conformational dependence of 
ChelpG $q(\mathrm{~S})$ also decreases on addition of the IL(SMD) model for most cases (seven out of 11). However, conformational dependence of ChelpG $q(S)$ increases for multiple ILs (see Figure 5) on addition of the IL(SMD) (e.g. $\left.\left[\mathrm{C}_{4} \mathrm{C}_{0} \mathrm{Im}\right]\left[\mathrm{HSO}_{4}\right]\right)$. The conformational dependence of the (nonburied) imidazolium ring ChelpG $q(\mathrm{C})$ also decreases on addition of the IL(SMD) model for all seven relevant ILs (ESI Figure S24 and S30). This observation suggests that the increase in conformational dependence for certain $q(S)$ on addition of the IL(SMD) is due to errors associated with fitting $q(\mathrm{~S})$ for buried sulfur atoms.

$\left[\mathrm{S}_{2,2,2}\right]\left[\mathrm{NTf}_{2}\right]$ was the only IL studied for which $q(\mathrm{~S})$ shows significant (range $>0.1$ e) conformational dependence for all three calculation methods. [ $\left.\mathrm{S}_{2,2,2}\right]\left[\mathrm{NTf}_{2}\right]$ conformers can be divided into two groups (Figure 7), labelled as S-side and alkyl-side conformers. For S-side conformers, $\left[\mathrm{NTf}_{2}\right]^{-}$interacts directly with the sulfur centre in the cation (the $\mathrm{S}_{\text {cation }}$ to $\mathrm{N}_{\text {anion }}$ distance is $\sim 2.9 \AA$ for most ion pair S-side conformers, ESI Figure S28). For alkyl-side conformers, $\left[\mathrm{NTf}_{2}\right]^{-}$sits further from the sulfur centre in the cation and interacts only with the alkyl chains $\left(S_{\text {cation }}\right.$ to $N_{\text {anion }}$ distances range from $3.8 \AA$ to $5.5 \AA$ for different alkyl-side ion pair conformers). $q(\mathrm{~S})$ for the $\left[\mathrm{S}_{2,2,2}\right]^{+}$cation for the $\mathrm{S}$-side conformers consistently have a more positive charge compared to alkyl-side conformers (ESI Figure S25). The increased $q(\mathrm{~S})$ from the $\left[\mathrm{S}_{2,2,2}\right]^{+}$cation in $\mathrm{S}$-side conformers results from the decreased separation between sulfur from the cation and nitrogen from the $\left[\mathrm{NTf}_{2}\right]^{-}$anion; the negative charge on the nitrogen from the $\left[\mathrm{NTf}_{2}\right]^{-}$anion stabilises a more positive charge on the sulfur atom in the $\left[\mathrm{S}_{2,2,2}\right]^{+}$cation.

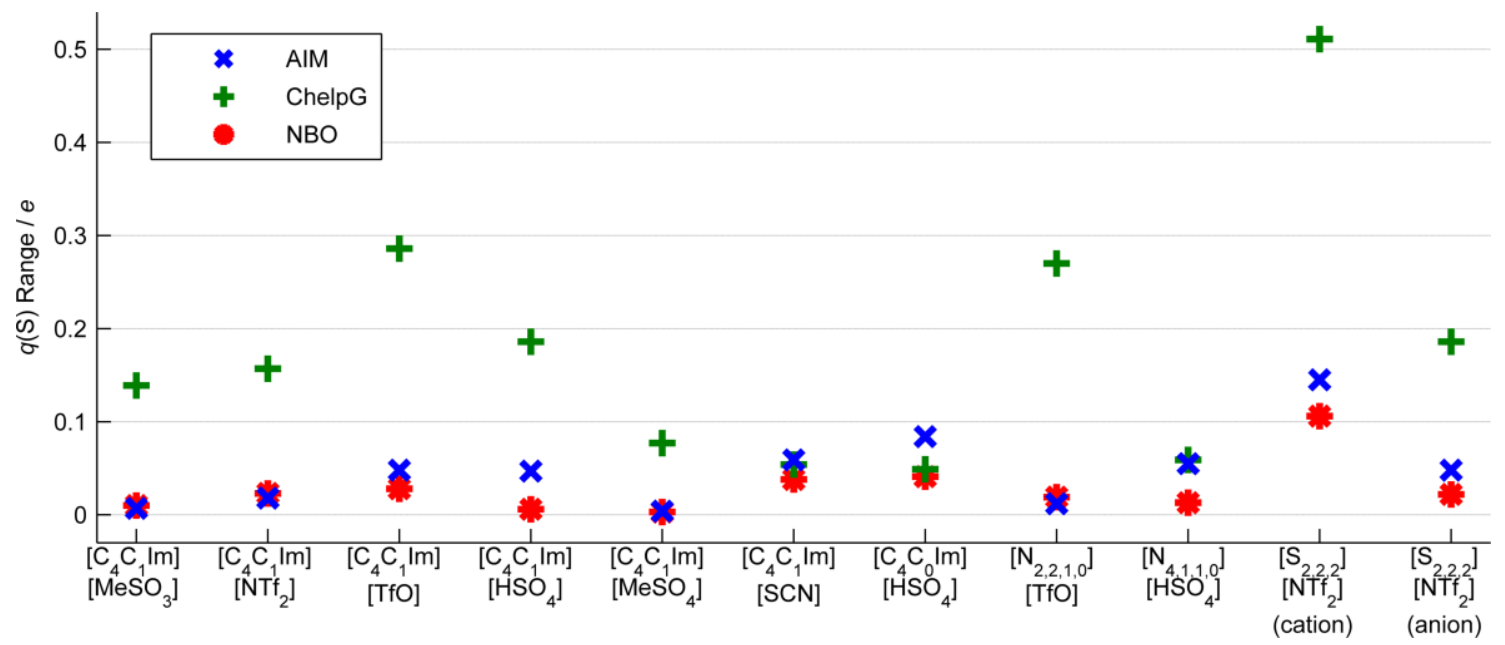

Figure 6. Range in the values of the atomic charges of sulfur, $q(\mathrm{~S})$, for ion pair (GP) conformers for all three $q(\mathrm{~S})$ calculation methods. In each case, the $q(\mathrm{~S})$ range is the difference between the maximum and minimum $q(S)$ calculated for a conformer (a larger range corresponds to a greater conformational dependence). The closer that the range value is to zero, the smaller the conformational dependence is for that IL using that $q(\mathrm{~S})$ method. 
a)

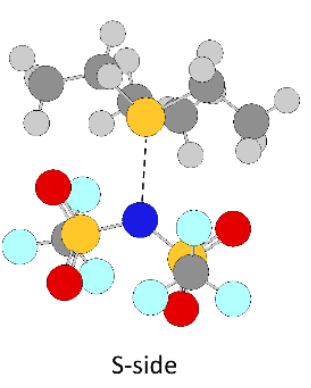

b)
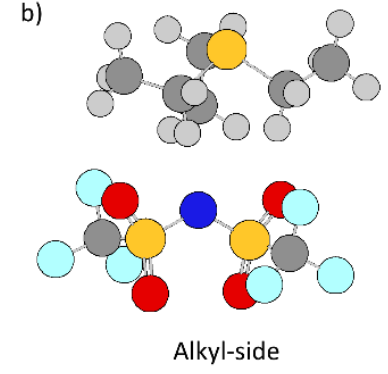

Figure 7. The two types of ion pair conformer identified for $\left[\mathrm{S}_{2,2,2}\right]\left[\mathrm{NTf}_{2}\right]$. Depicted structures were optimised in the gas phase (GP). (a) S-side conformer; $\left[\mathrm{NTf}_{2}\right]^{-}$interacts directly with the sulfur atom of the cation. (b) Alkyl-side conformer; $\left[\mathrm{NTf}_{2}\right]^{-}$interacts only with the ethyl groups of the cation. The dashed line in (a) emphasises the $\mathrm{N}-\mathrm{S}$ interaction. Atom colours are: $\mathrm{S}$ (yellow), C (grey), H (white), N (blue), O (red) and F (turquoise). 


\section{Discussion}

Correlations between $q(S)$ and $E_{\mathrm{B}}$ (and $q(\mathrm{~S})$ and $E_{\mathrm{NEXAFS}}$ ) were found to be almost identical for ion pair (GP) and ion pair IL(SMD) calculations. Therefore, the following discussion applies to both sets of data (Figure 8 for ion pair GP, ESI Figure S31 and S32 for ion pair IL(SMD) results).

\subsection{NEXAFS spectroscopy and XPS as measurements of $q(\mathrm{~S})$}
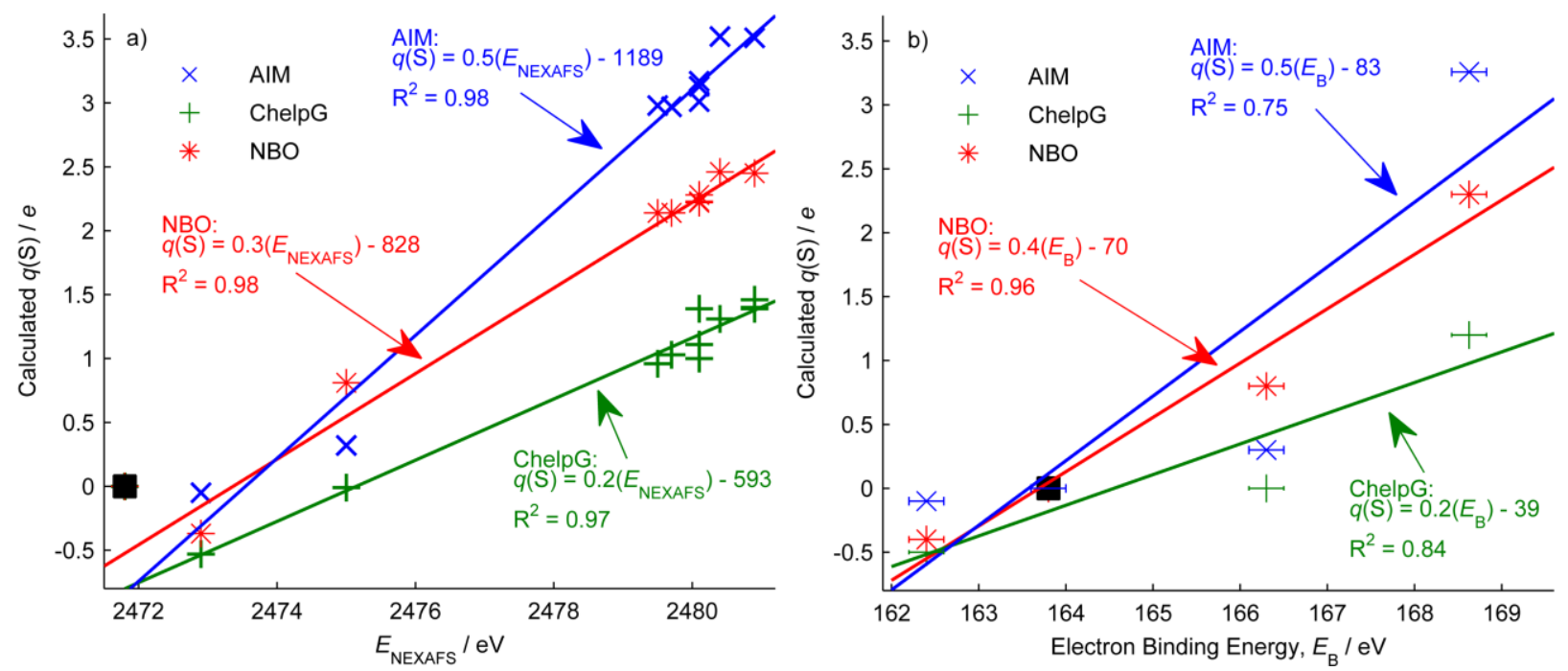

Figure 8. Comparison of calculated atomic charge of sulfur, $q(\mathrm{~S})$, with: (a) $S$ is $E_{\mathrm{NEXAFS}}$ and (b) $S 2 p_{3 / 2} E_{B}$. All charges are calculated from ion pair (GP) and are from an unweighted average of all conformers. The black square represents the data point for $\mathrm{S}_{8}$. The $\mathrm{S}_{8}$ data point was excluded from the linear regression for the $S 1 s E_{\text {NEXAFS }}$ data plot in (a), as the $S_{8} E_{\text {NEXAFS data }}$ point is a very large outlier (see main text for explanation). Note all [YSO $]^{-}$data points have been averaged in (b), so that they do not dominate the linear regression analysis (Figure ESI S31 for a version without all $\left[\mathrm{YSO}_{x}\right]^{-}$averaged).

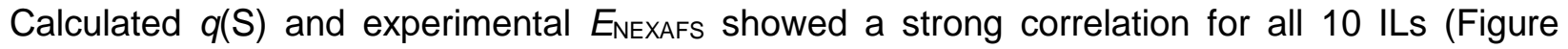
10a). The strong correlation between ENEXAFS and calculated $q(\mathrm{~S})$ for $\left[\mathrm{YSO}_{x}\right]^{-}-$based ILs suggests that the $S$ 1s $\rightarrow$ CB transitions probe similar excited states for these ILs. The similarity between the $S$ 1s edge shapes (Figure $3 b$ ) provides further evidence that similar excited states contribute to $E_{\mathrm{NEXAFS}}$ for $\left[\mathrm{YSO}_{x}\right]^{-}$-based ILs. It was necessary to exclude the $\mathrm{S}_{8}$ data point from the linear regression of $E_{\mathrm{NEXAFS}}$ versus $q(\mathrm{~S})$, as the $\mathrm{S}_{8}$ data point is a very large outlier. The deviation of the $S_{8} E_{\text {NEXAFS }}$ value is expected to be as a result of large energy differences between the CB energy in ILs and $S_{8}$. Therefore, NEXAFS spectroscopy can be a highly sensitive probe of $q(A)$, but only for systems for which similar excited states contribute to $E_{\text {NEXAFS. }}$ Therefore, NEXAFS spectroscopy is a suitable technique for probing small differences in $q(\mathrm{~A})$ between systems with similar chemical structures (e.g. [YSO $]^{-}$-based ILs). $E_{\mathrm{NEXAFS}}$ suggests that for $\left[\mathrm{YSO}_{x}\right]^{-}$-based ILs $q(\mathrm{~S})$ increases in the order: $\left[\mathrm{NTf}_{2}\right]^{-}<\left[\mathrm{MeSO}_{3}\right]^{-} \approx\left[\mathrm{TfO}^{-}<\right.$ $\left[\mathrm{MeSO}_{4}\right]^{-}<\left[\mathrm{HSO}_{4}\right]^{-}$. 
$E_{\mathrm{B}}$ for the $\left[\mathrm{YSO}_{x}\right]^{-}-$based ILs shows no linear correlation with $q(\mathrm{~S})$ (ESI Figure S31). The lack of linear correlation is because the differences in $E_{\mathrm{B}}$ are significantly smaller than the differences in $\Delta \beta / 2$, i.e. the final state effects are too large to enable conclusions to be drawn from $E_{\mathrm{B}}$. XPS is too insensitive to probe differences in $q(\mathrm{~S})$ between the [YSO $]^{-}$-based ILs, as noted in Section 3.1. Therefore, the XPS data points for [YSO $]^{-}$-based ILs were averaged to a single point when plotted against $q(\mathrm{~S})$ (Figure 10b), so that the nine XPS data points for [YSO $\mathrm{YS}^{-}$ -based ILs do not disproportionally affect the linear regression analysis. The $\mathrm{S}_{8}$ data point was included in the linear regression of $E_{\mathrm{B}}$ versus $q(\mathrm{~S})$, as the $\mathrm{S}_{8}$ data point is not an outlier (Figure 10b). $E_{\mathrm{B}}$ correlated linearly with $q(\mathrm{~S})$ for $[\mathrm{SCN}]^{-},\left[\mathrm{S}_{2,2,2}\right]^{+}, \mathrm{S}_{8}$ and $\left[\mathrm{YSO}_{x}\right]^{-}$, suggesting $q(\mathrm{~S})$ increases in the order: $[\mathrm{SCN}]^{-}<\mathrm{S}_{8}<\left[\mathrm{S}_{2,2,2}\right]^{+}<\left[\mathrm{YSO}_{x}\right]^{-}$. However, with only four data points in this fit, the correlation must be treated with a little caution.

We have found that XPS was superior to NEXAFS spectroscopy for detecting large differences in $q(\mathrm{~A})$ between systems with very different chemical structures (e.g. $\mathrm{S}_{8}$ compared to ILs). For example, $\left[\mathrm{C}_{4} \mathrm{C}_{1} \mathrm{Im}\right][\mathrm{SCN}]$ gave both the most negative $q(\mathrm{~S})$ and smallest $E_{\mathrm{B}}$ (but not the smallest $E_{\text {NEXAFS}}$ ). However, NEXAFS spectroscopy was superior to XPS for probing small differences in $q(\mathrm{~S})$ between highly similar systems (i.e. the $\left[\mathrm{YSO}_{x}\right]^{-} \mathrm{ILs}$ ).

Overall, the combination of $E_{\mathrm{B}}$ and $E_{\mathrm{NEXAFS}}$ suggests that $q(\mathrm{~S})$ increases in the order [SCN] ${ }^{-}<$ $\left[\mathrm{S}_{2,2,2}\right]^{+}<\mathrm{S}_{8}<\left[\mathrm{NTf}_{2}\right]^{-}<\left[\mathrm{MeSO}_{3}\right]^{-} \approx\left[\mathrm{TfO}^{-}<\left[\mathrm{MeSO}_{4}\right]^{-}<\left[\mathrm{HSO}_{4}\right]^{-}\right.$. The series of non- $\left[\mathrm{YSO}_{x}\right]^{-}-$ based ILs is assigned based on $E_{\mathrm{B}}$ values, whereas the [YSO$]^{-}$series is assigned based on $E_{\text {NEXAFS }}$ and calculated $q(\mathrm{~S})$. The observed trends in $q(\mathrm{~S})$ can all be rationalised qualitatively by considering the Pauling electronegativity $(\chi)$ of the atoms covalently bonded to sulfur; $\chi$ values are also used to assign oxidation states ${ }^{57,58}$. For example, $q(\mathrm{~S})$ is more positive in $\left[\mathrm{HSO}_{4}\right]^{-}$ compared with [ $\mathrm{TfO}^{-}$, as sulfur is covalently bound to four oxygen atoms $(\chi \mathrm{O} \approx 3.5)$ in $\left[\mathrm{HSO}_{4}\right]^{-}$ as opposed to three oxygen atoms and one carbon $\left(\chi_{\mathrm{C}} \approx 2.5\right)$ in $[\mathrm{TfO}]^{-}$.

\subsection{Comparing $q(\mathrm{~S})$ methods}

AIM, NBO and ChelpG $q(\mathrm{~S})$ were all found to correlate well with $E_{\text {NEXAFS }}\left(R^{2}=0.97\right.$ to $R^{2}=$ 0.98 ). The similar correlation with $E_{\mathrm{NEXAFS}}$ is primarily a result of the methods predicting similar trends in $q(\mathrm{~S})$ for the series of [YSO $]^{-}$ILs. For example, $q(\mathrm{~S})$ increases by 0.4 e to 0.5 e from $\left[\mathrm{C}_{4} \mathrm{C}_{1} \mathrm{Im}\right]\left[\mathrm{NTf}_{2}\right]$ to $\left[\mathrm{C}_{4} \mathrm{C}_{1} \mathrm{Im}\right]\left[\mathrm{HSO}_{4}\right]$ for all three methods of calculating $q(\mathrm{~S})$.

NBO $q(\mathrm{~S})$ show a good correlation with $E_{B}\left(\mathrm{R}^{2}=0.96\right)$, and ChelpG $q(\mathrm{~S})$ also show reasonable agreement with $E_{\mathrm{B}}\left(\mathrm{R}^{2}=0.84\right)$. The relatively poor correlation between $E_{\mathrm{B}}$ and $\mathrm{AIM} q(\mathrm{~S}), \mathrm{R}^{2}=$ 0.75 , suggests that AIM is an unsuitable method for assigning $q(A)$ in ILs. As both NBO and ChelpG $q(\mathrm{~S})$ correlate well with experiment, the use of either method for ILs is supported by our results.

A disadvantage of using ChelpG $q(\mathrm{~S})$ for ILs is the increased conformational dependence compared to AIM and NBO. The ion pair conformational dependence of ChelpG $q(\mathrm{~S})$ is interpreted as an artefact of the fitting process, based on three pieces of evidence. First, the 
low conformational dependence of both AIM and NBO $q(S)$ methods. Second, the lack of a counterion effect on $E_{\text {NEXAFS }}$ values suggests that only covalent interactions significantly affect $q(\mathrm{~S})$, whereas ion pair conformers vary mainly in the position of the anion relative to the cation. Third, the increase in conformational dependence for $q(S)$ for multiple ILs on addition of the IL(SMD) model, despite the opposite trend being observed both for other $q(S)$ methods and other non-buried atoms in the same ILs (see Section 3.2.3). The combination of these results suggest an unphysical basis to the ChelpG conformational dependence, with the corollary that ChelpG should not be used to interpret small $(<0.3$ e) differences in $q(A)$.

For $\left[\mathrm{YSO}_{x}\right]^{-}$-based ILs, there is a clear difference in the magnitude of $q(\mathrm{~S})$ for the three different charge methods used here. For [YSO $]^{-}$-based ILs, AIM $q(\mathrm{~S}) \sim 3.3 e, \mathrm{NBO} q(\mathrm{~S}) \sim 2.3 e$ and ChelpG $q(S) \sim 1.2$ e. Such a difference is very significant, and could lead to very different intermolecular interactions for ILs. However, when one also considers $q\left(\mathrm{SO}_{x}\right)$ the picture changes considerably. For $\left[\mathrm{HSO}_{4}\right]^{-},\left[\mathrm{MeSO}_{4}\right]^{-}$, [ $\left.\mathrm{MeSO}_{3}\right]^{-}$and $[\mathrm{TfO}]^{-}$the $\mathrm{SO}_{x}$ unit is $\mathrm{SO}_{3}$, and for $\left[\mathrm{NTf}_{2}\right]^{-}$the $\mathrm{SO}_{x}$ unit is $\mathrm{SO}_{2}$. Overall, $q\left(\mathrm{SO}_{x}\right)$ was relatively consistent for each IL across the three different charge methods (ESI Table S8). Therefore, we can conclude that the $\mathrm{SO}_{x}$ groups have similar $q\left(\mathrm{SO}_{x}\right)$, independent of the charge method used.

In this work we focused on methods applied to calculations using atom-centred basis sets. However, our experimental data can provide a benchmark for calculations using different methods of obtaining $q(\mathrm{~S})$. For example, calculations using plane wave basis sets can be used to calculate $q(A)$ (e.g. from Wannier functions or using the Blöchl charges methods). ${ }^{78,79}$ Such methods have been used for a wide range of ILs. ${ }^{32,80-82}$ 


\section{Conclusions}

The validity of both NEXAFS spectroscopy and XPS for investigating atomic charges has been tested by comparing trends in sulfur electron density derived from the two experimental techniques. NEXAFS spectroscopy and XPS were found to be complimentary techniques. XPS binding energies, $E_{\mathrm{B}}$, can be used to detect large differences in sulfur electron density between structurally diverse ILs, whereas NEXAFS edge energies can be used to detect small differences in sulfur electron density between systems that have sulfur in similar chemical environments. For both techniques care must be exercised when interpreting results in terms of atomic charge. In particular, differences in sulfur 1s XPS $E_{\mathrm{B}}<0.5 \mathrm{eV}$ should be treated with care when making inferences about the atomic charge of sulfur, as demonstrated by our Auger electron spectroscopy data. In terms of applying our estimate of $E_{\mathrm{B}}<0.5 \mathrm{eV}$ to other core orbitals for other elements, it is very difficult to use Auger electron spectroscopy to probe the final state effects of the very important second period elements (e.g. C, N and O), as their KLL Auger transitions involve valence orbitals, making analysis far more complicated than for the $S$ KLL Auger. Therefore, we expect our $E_{\mathrm{B}}<0.5 \mathrm{eV}$ value measured using the $S \mathrm{KLL}$ Auger transition to be the best experimental estimate of a lower limit for interpreting $E_{\mathrm{B}}$ shifts in terms of atomic charge for ILs.

ChelpG and NBO were both found to be reasonable methods for calculating $q(\mathrm{~S})$ in ILs, based on agreement with both NEXAFS spectroscopy and XPS results, whereas AIM is not recommended. NBO was found to be the best overall method to obtain $q(\mathrm{~S})$, owing to the strong correlation with experimental results and low conformational dependence. Despite the good agreement with experimental trends, ChelpG displayed an unphysical conformational dependence of $\approx 0.1 e$ to $0.3 e$ for $q(S)$ and $q(C)$. Therefore, small differences $(<0.3 e)$ in ChelpG atomic charges should not be interpreted as significant, and multiple conformers should be considered if using ChelpG. Only small differences in individual $q(S)$ were observed between lone ion (GP) and ion pair IL(SMD) model systems, indicating that ion-ion interactions do not strongly influence individual atomic charges.

The combined experimental and computational results allowed the order of $q(\mathrm{~S})$ to be determined for the ILs tested: $[\mathrm{SCN}]^{-}<\left[\mathrm{S}_{2,2,2}\right]^{+}<\mathrm{S}_{8}<\left[\mathrm{NTf}_{2}\right]^{-}<\left[\mathrm{MeSO}_{3}\right]^{-} \approx[\mathrm{TfO}]^{-}<\left[\mathrm{MeSO}_{4}\right]^{-} \approx$ $\left[\mathrm{HSO}_{4}\right]^{-}$. Furthermore, for all systems studied it was found that $q(\mathrm{~S})$ was dependent primarily on the local covalent bonding environment and not on intermolecular interactions. In particular, the counterion was found to have very little effect on $q(\mathrm{~S})$.

\section{Acknowledgements}

KRJL acknowledges Imperial College London for the award of a Junior Research Fellowship and the Royal Society for the award of a University Research Fellowship. We acknowledge the EPSRC for the award of a DTA studentship (RMF) and an EPSRC grant for the Kratos LiPPS XPS instrument EP/K005138/1. XMaS and the ESRF are thanked for awarding beamtime on BM28 (the XMaS beamline is a mid-range facility supported by the EPSRC). 


\section{References}

1. J. P. Hallett and T. Welton, Chem. Rev., 2011, 111, 3508-3576.

2. F. Zhou, Y. M. Liang and W. M. Liu, Chem. Soc. Rev., 2009, 38, 2590-2599.

3. M. Palacio and B. Bhushan, Tribol. Lett., 2010, 40, 247-268.

4. $\quad$ P. Hapiot and C. Lagrost, Chem. Rev., 2008, 108, 2238-2264.

5. D. R. MacFarlane, N. Tachikawa, M. Forsyth, J. M. Pringle, P. C. Howlett, G. D. Elliott, J. H. Davis, M. Watanabe, P. Simon and C. A. Angell, Energy Environ. Sci., 2014, 7, 232250.

6. A. M. Fernandes, M. A. A. Rocha, M. G. Freire, I. M. Marrucho, J. A. P. Coutinho and L. M. N. B. F. Santos, J. Phys. Chem. B, 2011, 115, 4033-4041.

7. A. Deyko, K. R. J. Lovelock, J. A. Corfield, A. W. Taylor, P. N. Gooden, I. J. VillarGarcia, P. Licence, R. G. Jones, V. G. Krasovskiy, E. A. Chernikova and L. M. Kustov, Phys. Chem. Chem. Phys., 2009, 11, 8544-8555.

8. P. A. Hunt, J. Phys. Chem. B, 2007, 111, 4844-4853.

9. A. D. McNaught and A. Wilkinson, IUPAC Compendium of Chemical Terminology, Blackwell Science, Oxford, 2nd edn., 1997.

10. F. Jensen, Introduction to Computational Chemistry, John Wiley \& Sons Ltd, West Sussex, 2007.

11. A. E. Reed, R. B. Weinstock and F. Weinhold, J. Chem. Phys., 1985, 83, 735-746.

12. A. E. Reed, L. A. Curtiss and F. Weinhold, Chem. Rev., 1988, 88, 899-926.

13. C. M. Breneman and K. B. Wiberg, J. Comput. Chem., 1990, 11, 361-373.

14. R. F. W. Bader, Accounts Chem. Res., 1985, 18, 9-15.

15. R. F. W. Bader, Chem. Rev., 1991, 91, 893-928.

16. J. Rigby and E. I. Izgorodina, Phys. Chem. Chem. Phys., 2013, 15, 1632-1646.

17. R. M. Fogarty, R. P. Matthews, R. G. Palgrave, R. A. Bourne, K. Handrup, A. Brandt, T. Vander Hoogerstraete, P. A. Hunt and K. R. J. Lovelock, 2017, In preparation.

18. R. M. Fogarty, K. R. J. Lovelock and P. A. Hunt, 2017, In preparation.

19. A. V. Marenich, C. J. Cramer and D. G. Truhlar, J. Phys. Chem. B, 2009, 113, 63786396.

20. V. S. Bernales, A. V. Marenich, R. Contreras, C. J. Cramer and D. G. Truhlar, J. Phys. Chem. B, 2012, 116, 9122-9129.

21. J. N. Canongia Lopes, J. Deschamps and A. A. H. Pádua, J. Phys. Chem. B, 2004, 108, 2038-2047.

22. T. G. A. Youngs, M. G. Del Popolo and J. Kohanoff, J. Phys. Chem. B, 2006, 110, 56975707.

23. Z. P. Liu, T. Chen, A. Bell and B. Smit, J. Phys. Chem. B, 2010, 114, 4572-4582.

24. C. G. Hanke, S. L. Price and R. M. Lynden-Bell, Mol. Phys., 2001, 99, 801-809.

25. E. Choi, J. G. McDaniel, J. R. Schmidt and A. Yethiraj, J. Phys. Chem. Lett., 2014, 5, 2670-2674.

26. M. Kohagen, M. Brehm, J. Thar, W. Zhao, F. Müller-Plathe and B. Kirchner, J. Phys. Chem. B, 2011, 115, 693-702.

27. A. R. Zolghadr, M. H. Ghatee and F. Moosavi, Chem. Phys., 2016, 475, 23-31.

28. R. Ishizuka and N. Matubayasi, J. Chem. Theory Comput., 2016, 12, 804-811.

29. G. Garcia, M. Atilhan and S. Aparicio, J. Mol. Liq., 2015, 211, 506-514.

30. L. K. Scarbath-Evers, P. A. Hunt, B. Kirchner, D. R. MacFarlane and S. Zahn, Phys. Chem. Chem. Phys., 2015, 17, 20205-20216.

31. T. G. A. Youngs and C. Hardacre, ChemPhysChem, 2008, 9, 1548-1558.

32. O. Hollóczki, F. Malberg, T. Welton and B. Kirchner, Phys. Chem. Chem. Phys., 2014, 16, 16880-16890.

33. K. C. Gross, P. G. Seybold and C. M. Hadad, Int. J. Quantum Chem., 2002, 90, 445458. 
34. A. V. Marenich, S. V. Jerome, C. J. Cramer and D. G. Truhlar, J. Chem. Theory Comput., 2012, 8, 527-541.

35. E. I. Izgorodina, M. Forsyth and D. R. MacFarlane, Phys. Chem. Chem. Phys., 2009, 11, 2452-2458.

36. T. Cremer, C. Kolbeck, K. R. J. Lovelock, N. Paape, R. Wölfel, P. S. Schulz, P. Wasserscheid, H. Weber, J. Thar, B. Kirchner, F. Maier and H. P. Steinrück, Chem.-Eur. J., 2010, 16, 9018-9033.

37. W. F. Egelhoff, Surf. Sci. Rep., 1987, 6, 253-415

38. P. S. Bagus, F. Illas, G. Pacchioni and F. Parmigiani, J. Electron Spectrosc. Relat. Phenom., 1999, 100, 215-236.

39. U. Gelius, P. F. Heden, J. Hedman, B. J. Lindberg, R. Marine, R. Nordberg, C. Nordling and K. Siegbahn, Phys. Scr., 1970, 2, 70-80.

40. B. J. Lindberg, K. Hamrin, G. Johansson, U. Gelius, A. Fahlman, C. Nordling and K. Siegbahn, Phys. Scr., 1970, 1, 286-298.

41. C. Sleigh, A. P. Pijpers, A. Jaspers, B. Coussens and R. J. Meier, J. Electron Spectrosc. Relat. Phenom., 1996, 77, 41-57.

42. U. Gelius, B. Roos and P. Siegbahn, Chem. Phys. Lett., 1970, 4, 471-475.

43. D. N. Hendrickson, J. M. Hollander and W. L. Jolly, Inorg. Chem., 1969, 8, 2642-2647.

44. S. Men, K. R. J. Lovelock and P. Licence, Phys. Chem. Chem. Phys., 2011, 13, 1524415255.

45. B. B. Hurisso, K. R. J. Lovelock and P. Licence, Phys. Chem. Chem. Phys., 2011, 13, 17737-17748.

46. I. J. Villar-Garcia, K. R. J. Lovelock, S. Men and P. Licence, Chemical Science, 2014, 5, 2573-2579.

47. R. K. Blundell and P. Licence, Chem. Commun., 2014, 50, 12080-12083.

48. R. K. Blundell and P. Licence, Phys. Chem. Chem. Phys., 2014, 16, 15278-15288.

49. S. Men, D. S. Mitchell, K. R. J. Lovelock and P. Licence, ChemPhysChem, 2015, 16, 2211-2218.

50. A. R. Santos, R. K. Blundell and P. Licence, Phys. Chem. Chem. Phys., 2015, 17, $11839-11847$.

51. G. Hohlneicher, H. Pulm and H. J. Freund, J. Electron Spectrosc. Relat. Phenom., 1985, 37, 209-224.

52. G. Moretti, J. Electron Spectrosc. Relat. Phenom., 1998, 95, 95-144.

53. H. Dau, P. Liebisch and M. Haumann, Anal. Bioanal. Chem., 2003, 376, 562-583.

54. N. Weiher, E. Bus, L. Delannoy, C. Louis, D. E. Ramaker, J. T. Miller and J. A. van Bokhoven, J. Catal., 2006, 240, 100-107.

55. F. Zhang, P. Wang, J. Koberstein, S. Khalid and S. W. Chan, Surf. Sci., 2004, 563, 7482.

56. J. D. Grunwaldt, M. Caravati and A. Baiker, J. Phys. Chem. B, 2006, 110, 25586-25589.

57. A. Vairavamurthy, Spectroc. Acta Pt. A-Molec. Biomolec. Spectr., 1998, 54, 2009-2017.

58. F. Jalilehvand, Chem. Soc. Rev., 2006, 35, 1256-1268.

59. R. M. Fogarty, R. P. Matthews, M. T. Clough, C. R. Ashworth, A. Brandt, P. J. Corbett, R. G. Palgrave, R. A. Bourne, T. W. Chamberlain, T. Vander Hoogerstraete, P. Thompson, P. A. Hunt, N. A. Besley and K. R. J. Lovelock, 2017, Submitted.

60. A. Brandt, M. J. Ray, T. Q. To, D. J. Leak, R. J. Murphy and T. Welton, Green Chem., 2011, 13, 2489-2499.

61. C. Kolbeck, M. Killian, F. Maier, N. Paape, P. Wasserscheid and H. P. Steinrück, Langmuir, 2008, 24, 9500-9507.

62. I. J. Villar-Garcia, E. F. Smith, A. W. Taylor, F. L. Qiu, K. R. J. Lovelock, R. G. Jones and P. Licence, Phys. Chem. Chem. Phys., 2011, 13, 2797-2808. 
63. P. B. J. Thompson, B. N. Nguyen, R. Nicholls, R. A. Bourne, J. B. Brazier, K. R. J. Lovelock, S. D. Brown, D. Wermeille, O. Bikondoa, C. A. Lucas, T. P. A. Hase and M. A. Newton, J. Synchrot. Radiat., 2015, 22, 1426-1439.

64. A. D. Becke, Phys. Rev. A, 1988, 38, 3098-3100.

65. C. T. Lee, W. T. Yang and R. G. Parr, Phys. Rev. B, 1988, 37, 785-789.

66. M. J. Frisch, G. W. Trucks, H. B. Schlegel, G. E. Scuseria, M. A. Robb, J. R.

Cheeseman, G. Scalmani, V. Barone, B. Mennucci, G. A. Petersson, H. Nakatsuji, M.

Caricato, X. Li, H. P. Hratchian, A. F. Izmaylov, J. Bloino, G. Zheng, J. L. Sonnenberg,

M. Hada, M. Ehara, K. Toyota, R. Fukuda, J. Hasegawa, M. Ishida, T. Nakajima, Y.

Honda, O. Kitao, H. Nakai, T. Vreven, J. J. A. Montgomery, J. E. Peralta, F. Ogliaro, M.

Bearpark, J. J. Heyd, E. Brothers, K. N. Kudin, V. N. Staroverov, R. Kobayashi, J.

Normand, K. Raghavachari, A. Rendell, J. C. Burant, S. S. Iyengar, J. Tomasi, M. Cossi, N. Rega, J. M. Millam, M. Klene, J. E. Knox, J. B. Cross, V. Bakken, C. Adamo, J.

Jaramillo, R. Gomperts, R. E. Stratmann, O. Yazyev, A. J. Austin, R. Cammi, C. Pomelli, J. W. Ochterski, R. L. Martin, K. Morokuma, V. G. Zakrzewski, G. A. Voth, P. Salvador, J. J. Dannenberg, S. Dapprich, A. D. Daniels, Ö. Farkas, J. B. Foresman, J. V. Ortiz, J. Cioslowski and D. J. Fox, Gaussian 09, Revision D.01, 2009.

67. A. D. McLean and G. S. Chandler, J. Chem. Phys., 1980, 72, 5639-5648.

68. R. Krishnan, J. S. Binkley, R. Seeger and J. A. Pople, J. Chem. Phys., 1980, 72, 650654.

69. T. Clark, J. Chandrasekhar, G. W. Spitznagel and P. V. Schleyer, J. Comput. Chem., 1983, 4, 294-301.

70. M. J. Frisch, J. A. Pople and J. S. Binkley, J. Chem. Phys., 1984, 80, 3265-3269.

71. S. Grimme, J. Antony, S. Ehrlich and H. Krieg, J. Chem. Phys., 2010, 132, 154104.

72. S. Grimme, S. Ehrlich and L. Goerigk, J. Comput. Chem., 2011, 32, 1456-1465.

73. A. D. Becke and E. R. Johnson, J. Chem. Phys., 2005, 123, 154101.

74. A. D. Becke and E. R. Johnson, J. Chem. Phys., 2006, 124, 014104.

75. P. A. Hunt and I. R. Gould, J. Phys. Chem. A, 2006, 110, 2269-2282.

76. T. A. Keith, AIMALL, 2014.

77. B. J. K. Glendening E D, Reed A E, Carpenter J E, Bohmann J A, Morales C M and Weinhold F, NBO 5.0 Program, 2001.

78. P. E. Blochl, J. Chem. Phys., 1995, 103, 7422-7428.

79. B. Kirchner and J. Hutter, J. Chem. Phys., 2004, 121, 5133-5142.

80. F. Dommert, J. Schmidt, C. Krekeler, Y. Y. Zhao, R. Berger, L. Delle Site and C. Holm, J. Mol. Liq., 2010, 152, 2-8.

81. J. Schmidt, C. Krekeler, F. Dommert, Y. Y. Zhao, R. Berger, L. Delle Site and C. Holm, J. Phys. Chem. B, 2010, 114, 6150-6155.

82. K. Wendler, F. Dommert, Y. Y. Zhao, R. Berger, C. Holm and L. Delle Site, Faraday Discuss., 2012, 154, 111-132. 